\title{
An Ac/Ds-mediated gene trap system for functional genomics in barley
}

\author{
Katina Lazarow*1,2 and Stephanie Lütticke ${ }^{1}$
}

\author{
Address: ${ }^{1}$ Biocenter Klein Flottbek, University of Hamburg, Ohnhorststrasse 18, 22609 Hamburg, Germany and ${ }^{2}$ Institute of Biology/Applied \\ Genetics, Free University Berlin, Albrecht-Thaer-Weg 6, 14195 Berlin, Germany \\ Email: Katina Lazarow* - lazarow@zedat.fu-berlin.de; Stephanie Lütticke - luetticke.s@eppendorf.de \\ * Corresponding author \\ Published: 29 January 2009 \\ BMC Genomics 2009, 10:55 \\ This article is available from: http://www.biomedcentral.com/147I-2/64/10/55 \\ (C) 2009 Lazarow and Lütticke; licensee BioMed Central Ltd. \\ This is an Open Access article distributed under the terms of the Creative Commons Attribution License (http://creativecommons.org/licenses/by/2.0), \\ which permits unrestricted use, distribution, and reproduction in any medium, provided the original work is properly cited.
}

\begin{abstract}
Background: Gene trapping is a powerful tool for gene discovery and functional genomics in both animals and plants. Upon insertion of the gene trap construct into an expressed gene, splice donor and acceptor sites facilitate the generation of transcriptional fusions between the flanking sequence and the reporter. Consequently, detection of reporter gene expression allows the identification of genes based on their expression pattern. Up to now rice is the only cereal crop for which gene trap approaches exist. In this study we describe a gene trap system in barley (Hordeum vulgare L.) based on the maize transposable elements Ac/Ds.
\end{abstract}

Results: We generated gene trap barley lines by crossing Ac transposase expressing plants with multiple independent transformants carrying the Ds based gene trap construct GTDsB. Upstream of the $\beta$-Glucuronidase start codon GTDsB carries splice donor and acceptor sites optimized for monocotyledonous plants. DNA blot analysis revealed GTDsB transposition frequencies of $11 \%$ and $26 \%$ in the $F_{1}$ and $F_{2}$ generation of gene trap lines and perpetuation of transposition activity in later generations. Furthermore, analysis of sequences flanking transposed GTDsB elements evidenced preferential insertion into expressed regions of the barley genome. We screened leaves, nodes, immature florets, pollinated florets, immature grains and seedlings of $F_{2}$ plants and detected GUS expression in $5 I \%(72 / 14 I)$ of the plants. Thus, reporter gene expression was found in 24 of the $28 \mathrm{~F}_{1}$ lines tested and in progeny of all GTDsB parental lines.

Conclusion: Due to the frequent transposition of GTDsB and the efficient expression of the GUS reporter gene, we conclude that this Ac/Ds-based gene trap system is an applicable approach for gene discovery in barley. The successful introduction of a gene trap construct optimized for monocots in barley contributes a novel functional genomics tool for this cereal crop.

\section{Background}

Gene trapping has proved to be an effective strategy for functional genomics and gene discovery in both animals and plants [1-3]. Gene trap constructs are designed to detect the expression of a chromosomal gene upon insertion into its transcribed region. Consequently, the inserted gene trap reports the gene expression pattern and a visible mutant phenotype is not required for gene identification. The direct visual assessment of reporter gene expression enables the identification of functionally redundant genes, genes that operate in multiple developmental stages and genes whose functions in later develop- 
ment are obscured by an early lethal phenotype, all of them not easily amenable to classic genetic analysis. Several types of "trapping" systems, differing in the reporter gene constructs used, have been developed: enhancer trap, gene trap and promoter trap [2,3]. The gene traps are characterized by splice acceptor sites and sometimes an intron upstream of the reporter gene coding region. These structural features facilitate the production of in-frame reporter protein fusions regardless of insertion into intron or exon sequences.

Due to extensive knowledge about their transposition features, Activator ( $A c)$ and Dissociation (Ds) transposable elements from maize have been successfully utilized for insertional mutagenesis in heterologous plants [4]. With the aim to discover genes whose knockout does not display a visible mutant phenotype, Ac/Ds based gene trap systems were introduced in Arabidopsis [5] and rice [6]. Furthermore, different gene trap systems based on T-DNA transfer in Arabidopsis [7-9] and rice [10] and on recombination in Physcomitrella patens [11] have proven their usefulness for the study of developmental processes and gene discovery in plants.

In addition to its agricultural importance, barley evolved as a model species for the Triticeae $[12,13]$. Due to gene synteny and colinearity among the Triticeae genomes $[14,15]$ the diploid barley is considered a reference species especially for polyploid Triticeae members like wheat. Similar to maize and wheat the $4873 \mathrm{Mb}$ barley genome [16] is partitioned into gene-rich regions and large stretches of gene-poor repetitive DNA composed of numerous retrotransposons $[17,18]$. For barley many genomics resources exist, including more than 30 wellcharacterized genetic linkage maps, a large-insert Bacterial Artificial Chromosome (BAC) library and a barley microarray $[13,19,20]$. At present, more than 400000 expressed sequence tags (ESTs) are available [21] that cover a significant portion of the barley gene repertoire. The establishment of transformation systems [22-24] and the successful introduction of $A c / D s$ elements $[25,26]$ were the initial steps towards gene tagging approaches in barley $[25,12,27,28]$.

Up to now, gene trap and enhancer trap approaches in monocots have exclusively been reported in rice $[6,10,29,30]$. In this study, we report the introduction of an $A c / D s$-based gene trap system in barley, thus expanding the number of genomics tools available to the barley research community. A gene trap construct [31] designed to provide an increased gene trapping efficiency, particularly in monocotyledonous plants, was used to produce barley gene trap lines. The frequent transposition of the gene trap construct and efficient expression of the reporter gene in these lines demonstrate that this approach is a sig- nificant step towards large-scale gene trapping in this crop.

\section{Results \\ Generation of gene trap lines}

The maize transposable element Ac/Ds was chosen to construct a two-component gene trap system for barley. Two versions of $A c$ expressing either wild type transposase (TPase) or an N-terminally truncated transposase (TPase $_{103-807}$ [32]) under control of the native Ac promoter were used (Figure 1a). Both TPase-expressing elements were immobilized by removal of the five terminal bases from the 5 ' terminal inverted repeat (TIR) sufficient to abolish Ac transposition [33]. The non-autonomous $D s$ element named GTDsB carries the uidA reporter gene encoding $\beta$-glucuronidase (GUS) [31]. The reporter gene is preceded by engineered intron and triple splice acceptor sequences upstream of the ATG codon (Figure 1b). Each of the three constructs was stably transformed into barley cultivar Golden Promise by particle bombardment. To verify the integration of intact copies and estimate the transgene copy number, in order to select parental lines for crosses, we subjected independent lines, seven carrying Ac and 34 harbouring GTDsB, to DNA gel blot analysis. Eleven GTDsB lines with low (one to three), medium (four to seven) and high (up to 12) copy number and four TPase lines were selected as starter lines (Table 1). Two TPase lines express wild type TPase and two the truncated TPase $_{103-807}$ protein. The number of integrated Ac TPase copies was between one and four in the different lines. The expression of a functional TPase was confirmed with plants from all four TPase lines (C.K. Friedrich, personal communication) using a transient assay for TPase activity [34]. From crosses of the four TPase lines with each of the 11 GTDsB lines we obtained $F_{1}$ progeny for 30 different combinations.

\section{Analysis of GTDsB transposition}

DNA gel blot analysis was employed to study the transposition of GTDsB in the gene trap lines. In these experiments the occurrence of a new GTDsB-hybridizing DNA fragment in comparison to the corresponding GTDsB parental line was chosen as a criterion to indicate transposition of GTDsB. We performed analysis of GTDsB excision and reinsertion events in $79 \mathrm{~F}_{1}$ plants originating from 29 independent crosses. Nine plants (11\%) derived from six independent crosses showed novel hybridizing bands that were not present in the parental GTDsB lines (Table 1).

For a second set of experiments we rescued progeny harbouring both TPase and GTDsB constructs from 28 selfed $F_{1}$ plants $\left(F_{2}\right.$ parent, Table 1$)$, each derived from an independent cross of different parental lines. A total of $191 \mathrm{~F}_{2}$ plants, including an average of five siblings per independ- 
Table I: GTDsB transposition in $F_{1}$ and $F_{2}$ generation of gene trap lines

\begin{tabular}{|c|c|c|c|c|c|c|c|c|c|}
\hline \multicolumn{3}{|c|}{ Parental lines } & \multicolumn{2}{|c|}{$F_{1}$ generation } & \multicolumn{5}{|c|}{$\mathrm{F}_{2}$ generation } \\
\hline GTDsB line & GTDsB copies & TPase line $^{\mathrm{a}}$ & $\begin{array}{l}\text { No. plants } \\
\text { analysed }\end{array}$ & No. with tnp & $F_{2}$ parent & $\begin{array}{l}\text { No. plants } \\
\text { analysed }\end{array}$ & No. with tnp & $\begin{array}{l}\text { Independent } \\
\text { tnpc }\end{array}$ & No. $\mathrm{pa}^{\mathrm{d}}$ \\
\hline \multirow[t]{3}{*}{$2 \mathrm{a} / \mathrm{d}$} & $1-2$ & 2 & 3 & - & GT32 & 6 & 3 & 1 & - \\
\hline & & 4 & 9 & - & GT73 & 4 & 4 & 1 & - \\
\hline & & 7 & I & - & - & & & & \\
\hline \multirow[t]{4}{*}{23} & $1-2$ & 2 & 4 & - & GT33 & 4 & 1 & 1 & - \\
\hline & & 3 & 2 & I & GT29 & 4 & 4 & 3 & - \\
\hline & & 4 & I & - & GT39 & 1 & I & I & I \\
\hline & & 7 & 4 & 3 & GT4I & 5 & 5 & 2 & - \\
\hline \multirow[t]{2}{*}{$3 \mid \mathrm{B}$} & 2 & 4 & 4 & - & GT49 & 4 & 2 & 1 & 1 \\
\hline & & 7 & 5 & 2 & GT54 & 5 & 3 & I & - \\
\hline \multirow[t]{3}{*}{$6 \mathrm{a} / \mathrm{c}$} & $2-4$ & 2 & 1 & - & GT70 & 4 & - & - & - \\
\hline & & 4 & 1 & - & GT67 & 7 & - & - & 1 \\
\hline & & 7 & 2 & - & GT4 & 7 & 5 & 5 & I \\
\hline \multirow[t]{3}{*}{$3 \mid \mathrm{A}$} & 4 & 2 & 2 & - & GT38 & 6 & 6 & 2 & - \\
\hline & & 4 & I & - & - & & & & \\
\hline & & 7 & 6 & I & GT52 & 5 & - & - & - \\
\hline \multirow[t]{3}{*}{16} & $3-5$ & 2 & 2 & - & GTI9 & 4 & 3 & 1 & - \\
\hline & & 7 & 2 & - & GT37 & 7 & 2 & 2 & - \\
\hline & & 7 & 2 & - & GT40 & 4 & 4 & 2 & - \\
\hline \multirow[t]{2}{*}{$14 \mathrm{~A}$} & $5-6$ & 4 & 2 & - & GTI3 & 4 & 3 & 1 & 1 \\
\hline & & 7 & 3 & - & GT22 & 5 & - & - & 2 \\
\hline \multirow[t]{3}{*}{ II } & $5-8$ & 3 & 1 & I & GT82 & 3 & 3 & 1 & - \\
\hline & & 4 & 1 & - & GT66 & 3 & - & - & 1 \\
\hline & & 7 & 2 & - & GT80 & 54 & 16 & 10 & 3 \\
\hline \multirow[t]{3}{*}{10} & $6-7$ & 2 & 4 & - & GT9 & 7 & - & - & - \\
\hline & & 4 & 3 & - & GT2 & 7 & - & - & 5 \\
\hline & & 7 & 2 & - & GT6 & 7 & 1 & 1 & - \\
\hline \multirow[t]{2}{*}{$14 \mathrm{~B}$} & $8-10$ & 2 & 2 & - & GT23 & 4 & 2 & 2 & - \\
\hline & & 7 & 3 & I & GTI5 & 8 & 3 & 3 & 1 \\
\hline \multirow[t]{2}{*}{26} & 12 & 2 & 2 & - & GT35 & 4 & 3 & 3 & I \\
\hline & & 7 & 2 & - & GT63 & 8 & 5 & 5 & 3 \\
\hline Total & & & 79 & 9 & & 191 & 79 & 49 & 21 \\
\hline
\end{tabular}

aTPase line 3 and 4 carry four and two copies of the TPase construct respectively, whereas 2 and 7 carry one and four TPase 103-807 $_{\text {constructs }}$ respectively

bNumber of plants showing GTDsB transposition (tnp)

cNumber of plants with independent transposition events

dNumber of plants with phenotypic abnormality (pa)

ent cross, with the exception of lines GT39 and GT80 with one and 54 plants each, were analyzed. New GTDsBhybridizing bands were detected in $79 \mathrm{~F}_{2}$ plants $(41 \%)$ representing 21 of the $28 \mathrm{~F}_{1}$ gene trap lines (75\%). Examples of DNA hybridization patterns are shown in Figure 2. Unique hybridization patterns, suggesting independent transposition events, were found in $49 \mathrm{~F}_{2}$ plants $(26 \%)$. Independent transposition events can be due to either transposition in independent cells of the $\mathrm{F}_{1}$ plant, which subsequently were transmitted to progeny, or to somatic transposition in the $\mathrm{F}_{2}$ seedling (for example see Figure 2b, plants GT80/10 and GT80/13). In contrast, early transposition of GTDsB in the $\mathrm{F}_{1}$ generation may result in all progeny inheriting the same insertion (for example see Figure 2a, GT82/1-3). Additionally a transposition event having occurred in one of the barley tillers during the development of the $\mathrm{F}_{1}$ plant may lead to several but not all $\mathrm{F}_{2}$ siblings showing the same new GTDsB insertion (for example see Figure 2a, GT54/3-5). Transposition of GTDsB occurred in progeny of crosses with each of the 11 GTDsB parental lines (Table 1), evidencing that every independent parental GTDsB line carries transposition competent constructs.

The gene trap $\mathrm{F}_{2}$ population was also screened for visible phenotypic abnormalities. In 21 of the 191 (11\%) gene trap $\mathrm{F}_{2}$ plants deviations from barley wild type phenotype were observed (Table 1 ). These included reduced fertility $(4 / 21)$, aberrant leaf pigmentation $(4 / 21)$ and stunted growth $(9 / 21)$ (data not shown). Interestingly, in two 


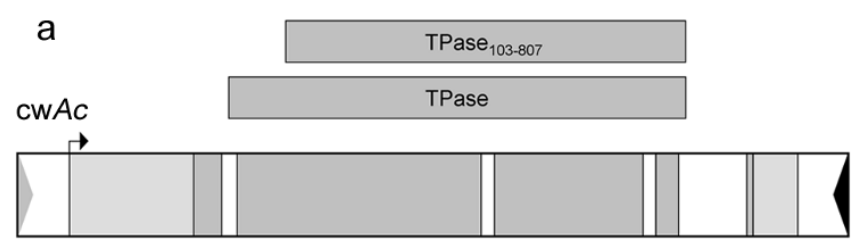

b

GTDsB

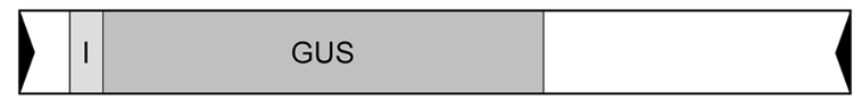

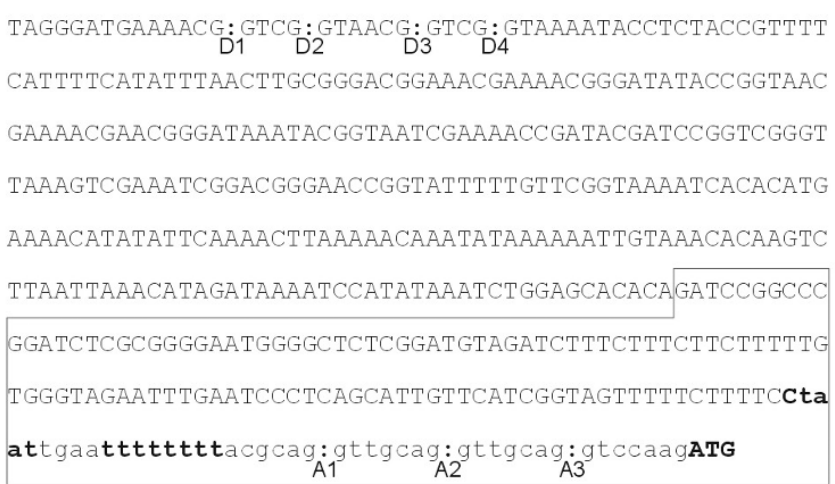

Figure I

Schematic diagrams of the Ac/Ds-derived constructs used for generation of gene trap lines. a The two cwAc constructs express a full-length 807 amino acids TPase and a $\mathrm{N}$-terminally truncated 705 amino acids TPase ${ }_{103-807}$, respectively, under control of the native Ac promoter. Both elements were immobilized by disruption of the $5^{\prime}$ terminal inverted repeat (gray arrowhead). The intact 3' terminal inverted repeat is shown as a black arrowhead. A small arrow indicates the transcription start. TPase protein coding sequences are indicated by dark-gray boxes. $\mathbf{b}$ The Ds-based gene trap construct GTDsB contains the uidA coding region (GUS), the 3' sequences of the first Actl intron from rice and a synthetic triple splice acceptor site (I).Ac sequences are depicted as an open box and the terminal inverted repeats are shown as filled arrowheads at the outer ends. The sequences of the putative splice donors (DI-D4), the synthetic splice acceptor sites (AI-A3) and the Actl intron (boxed sequence) existing in the GTDsB 5' subterminal region are shown. The branchpoint sequences and T-tract are bold typed.

plants, GT29/6 and GT39/6, showing asymmetric internodes leading to bending stems and stunted growth with shortened ears respectively, the phenotypic deviation coincided with an independent transposition event. A possible connection between the transposition event and the conspicuous phenotype must be examined in further experiments.
To prove the persistence of GTDsB transpositional activity in later generations, we subjected a total of $252 \mathrm{~F}_{4}$ plants originating from the $\mathrm{F}_{2}$ plants GT54/8, GT29/6, GT49/7 and GT41/3 to DNA gel blot analysis. In five of the 67 GT54/8 progeny $(7.5 \%), 22$ of the 64 GT29/6 progeny (34.4\%), 10 of the 59 GT49/7 progeny (17\%) and three of the 64 GT41/3 progeny (4.8\%) new GTDsB-hybridizing DNA fragments were detected. These transposition events must have occurred either in the $\mathrm{F}_{2}$ and $\mathrm{F}_{3}$ generation or in somatic tissue of the $\mathrm{F}_{4}$ plants.

\section{Sequence analysis of GTDsB flanking regions}

We employed TAIL-PCR [35] to obtain DNA sequences flanking transposed GTDsB constructs from gene trap $\mathrm{F}_{2}$ plants. In total, 32 genomic sequences ranging from 111 to $678 \mathrm{bp}$ were isolated and compared to publicly available databases using BLAST searches. We considered Expectation (E) values below 1e- 6 to assign a putative identity to a flanking sequence. As evidenced by similarity to expressed sequence tags (ESTs) from members of the Triticeae and maize, 19 of the 32 GTDsB insertions (59\%) are located in transcribed genomic regions (Table 2). Moreover, 15 GTDsB flanking sequences (47\%) show high identity to ESTs from barley (Table 2). Assuming an average sequence length of about $400 \mathrm{bp}$, the 419146 non-overlapping barley ESTs in the databases [21] represent approximately $168 \mathrm{Mb}$ of total sequence, or about $3 \%$ of the $4873 \mathrm{Mb}$ barley genome [16]. Consequently, a random fragment of barley DNA would have on average a 3\% chance of being homologous to a barley EST in the database. Considering that more than $80 \%$ of the barley genomic sequences are intergenic heterochromatin [36] and therefore not expressed, the frequent identity of the flanking genomic sequences to barley ESTs clearly indicates a preference for GTDsB insertion into coding regions.

\section{Expression of the GUS reporter}

The expression of the GUS reporter gene was assayed by histochemical GUS staining in $141 \mathrm{~F}_{2}$ plants, comprising 1 to 8 progeny of the 28 individual $F_{1}$ gene trap lines (Table 3). Staining for GUS expression was performed in leaves, nodes, immature florets, pollinated florets, immature grains and seedlings covering several stages of barley development. The leaves, nodes and immature florets were collected from developmental stage 49 defined following the Zadoks code system for growth staging in barley [37]. Pollinated florets, immature grains and seedlings represent developmental stages 65-69, 83-85 and 10 respectively. For the majority of the $141 \mathrm{~F}_{2}$ plants multiple explants were examined (one leaf, two nodes, 8 pollinated florets, 20 immature florets, 8 immature grains and 8 seedlings), resulting in a total of 5134 analysed explants. This experimental approach was chosen to enable the dis- 


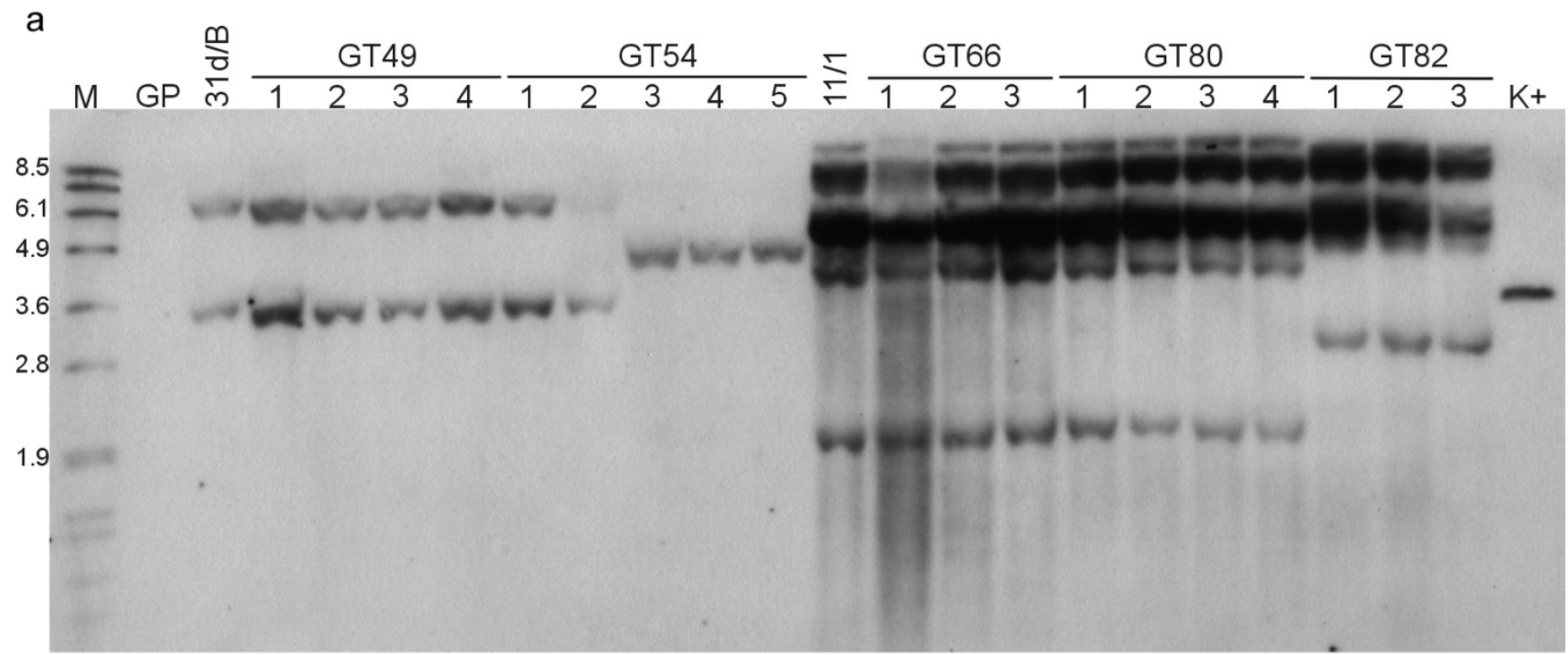

b

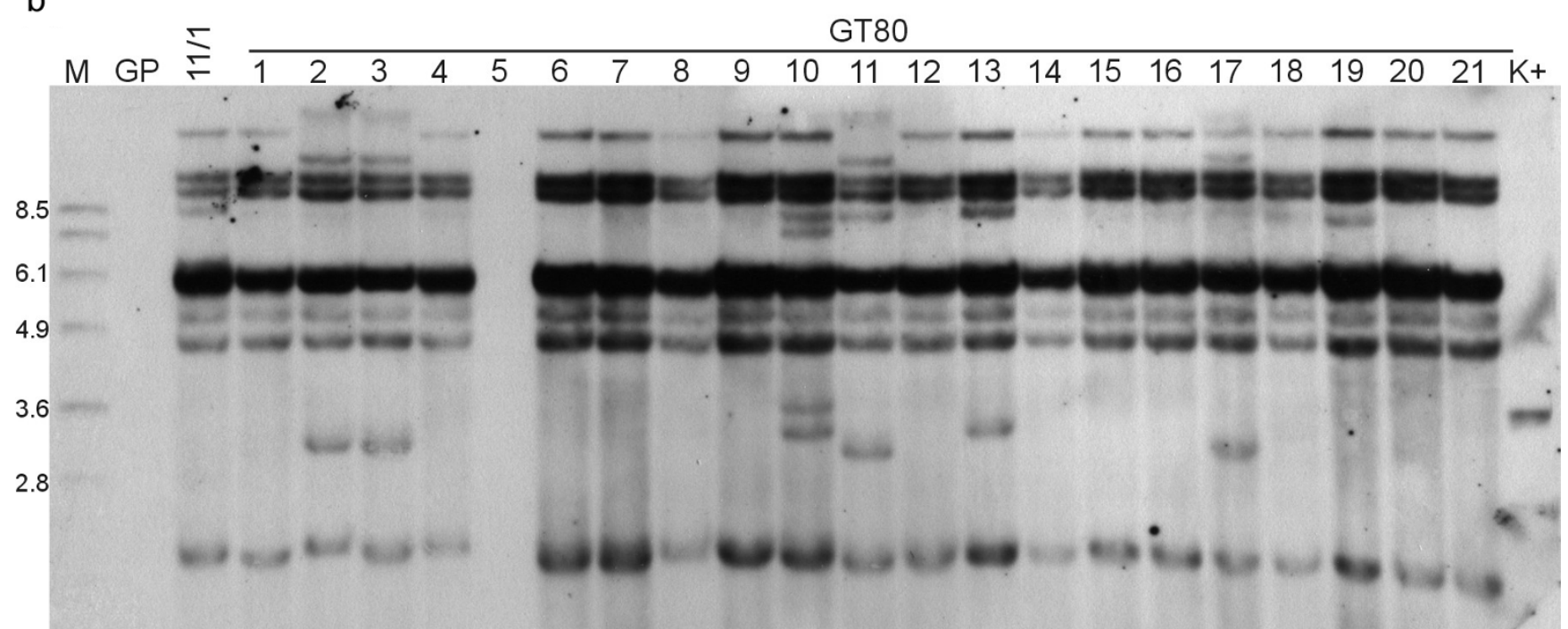

\section{Figure 2}

Representative DNA gel blot analysis of $F_{2}$ plants derived from five independent crosses. Genomic DNA of three to five $F_{2}$ siblings from lines GT49, GT54, GT66, GT80 and GT82 (a) and of $21 F_{2}$ siblings from line GT80 (b), as well as DNA of the GTDsB parental lines ( $3 \mathrm{I} / \mathrm{d} / \mathrm{B}$ and $\mathrm{II} / \mathrm{I}$ ) and Golden Promise wild type (GP) were digested with Bglll and blots were hybridized to a GUS probe. The numbers above each panel announce the individual plant identification, e.g. GT49/I in lane 4 (a). The numbers on the left side of each panel indicate the positions of size markers ( $M$ ) in kb.

tinction of somatic from heritable events. We assume that, if only one explant of a certain organ type shows GUS expression, it may be considered as a somatic event. In contrast, if the majority or all explants of the same organ type from a single plant exhibit an equal GUS expression pattern, the event may be transmitted to progeny. Due to the two-element approach, these inheritable events can be stabilized by segregation of the TPase construct and are amenable to further analysis.
Expression of the GUS reporter could be detected in 51\% $(72 / 141)$ of the analysed $F_{2}$ plants (Table 3$)$. Moreover, GUS expression was found in 24 of the $28 \mathrm{~F}_{1}$ lines and in progeny of all GTDsB parental lines used. Examples of GUS expression in various organs are shown in Figure 3. In immature florets and in pollinated florets GUS activity was primarily detected in the palea and lemma (for examples see Figure 3a and 3b). In addition, in three cases GUS activity appeared in the stigma and pistil (data not 
Table 2: GTDsB flanking sequences with similarity to ESTs in public databases

\begin{tabular}{|c|c|c|c|c|c|}
\hline $\mathrm{F}_{2}$ plant & Length (bp) & Organism & Accession number & E-value $^{\mathrm{a}}$ & Similarity (\%) \\
\hline \multirow[t]{2}{*}{ GT4/7 } & 603 & H. vulgare & CB88I303.I & $6 e-79$ & 91 \\
\hline & 517 & H. vulgare & CB880I26 & $2 e-97$ & 89 \\
\hline \multirow[t]{2}{*}{ GT29/I } & 561 & H. vulgare & CK566326 & le-09 & 89 \\
\hline & 537 & H. vulgare & U43284CDS & $9 e-29$ & 88 \\
\hline \multirow[t]{2}{*}{ GT37/I } & 111 & H. vulgare & CA0II566 & le-20 & 95 \\
\hline & 378 & H. vulgare & CB864I49 & $6 e-26$ & 98 \\
\hline \multirow[t]{2}{*}{ GT4I/I } & 678 & H. vulgare & BF620234 & e- 102 & 89 \\
\hline & 376 & H. vulgare & CB867749 & $9 e-22$ & 94 \\
\hline \multirow[t]{3}{*}{ GT4I/9 } & 304 & T. aestivum & CNOI0744 & le-66 & 88 \\
\hline & 503 & H. vulgare & BF616808 & $6 e-36$ & 82 \\
\hline & 327 & H. vulgare & AJ46I42I & le-60 & 100 \\
\hline \multirow[t]{2}{*}{ GT54/6 } & 316 & H. vulgare & CD056550 & e- 149 & 97 \\
\hline & 527 & T. aestivum & CV758685 & $3 e-16$ & 88 \\
\hline \multirow[t]{4}{*}{ GT63/5 } & 470 & H. vulgare & CB864987 & e- 108 & 93 \\
\hline & 133 & H. vulgare & CB881931 & $4 e-58$ & 97 \\
\hline & 124 & H. vulgare & BU966953 & $|e-| \mid$ & 94 \\
\hline & 193 & Z. mays & DN560626 & $9 e-83$ & 95 \\
\hline \multirow[t]{2}{*}{ GT82/4 } & 292 & H. vulgare & A) 473098 & $2 e-77$ & 98 \\
\hline & 356 & T. aestivum & BQI7029| & $2 e-13$ & 88 \\
\hline
\end{tabular}

aStatistical significance threshold for reporting matches against database sequences obtained after BLAST program search

shown). In all samples the GUS signals in culm nodes corresponded to the example shown in Figure 3d. The seedlings displayed GUS expression primarily in the scutellum (for example see Figure 3e). In five cases GUS activity could be observed in the roots (data not shown). In the majority of GUS positive seeds the expression was localized in the endosperm (for example see Figure $3 \mathrm{c}$ and $3 \mathrm{f}$ ). However, in three cases GUS signals were observed in the pericarp (data not shown).

Out of the 72 GUS positive plants 45 showed GUS expression restricted to one or two explants, even when occurring in several organs, indicating that the majority of the events is due to somatic transposition of GTDsB. In such cases only a limited portion of somatic tissue carries the new GTDsB insertion and can consequently be expected to express GUS. In contrast, in $14 \mathrm{~F}_{2}$ plants GUS expression was detected in the same tissue in at least $50 \%$ of the explants (Table 4) denoting candidates for heritable events. In eight of these candidates GUS expression was detected in scutellar tissue of seedlings (GT54/5-GT15/4) or in the endosperm of immature grains (GT63/4). Analysis of progeny will confirm the heritability of these gene trap events enabling identification of GTDsB integration sites.

The GUS staining frequency ranged between 3\% and 26\% in individual organs (Table 5). As expected, the highest frequencies of $26 \%$ and $24 \%$ were observed in grains and seedlings representing mostly tissues of the $\mathrm{F}_{3}$ generation. As a consequence of transposition in $\mathrm{F}_{3}$ tissues early events of the $\mathrm{F}_{3}$ generation can be detected in addition to events that occurred in the preceding generations.

\section{Analysis of spliced GUS transcripts}

The expression of GUS depends on the transcriptional fusion between the reporter open reading frame and upstream gene sequences following the insertion of GTDsB into a transcription unit. Consequently, correct and efficient splicing of the gene trap construct by the host spliceosome is crucial and has been already shown for GTDsB in transient experiments [31]. We aimed to demonstrate that splicing of stably integrated GTDsB constructs in the gene trap barley lines is accomplished just as accurately. For these experiments the gene trap line GT35 was chosen, since the same GUS expression pattern (Figure 3a) was found in $100 \%$ of the pollinated florets in all progeny tested, indicating an inheritable gene trap event (Table 4). Additionally, RNA gel blot analysis confirmed the occurrence of uidA-specific transcripts exceeding the size of the original uidA transcript by 1.1 and $0.4 \mathrm{~kb}$, thus indicating the presence of transcriptional fusions encoding GUS in the florets of gene trap line GT35 (data not shown). We used 5'-RACE (rapid amplification of cDNA ends [38]), to isolate spliced transcripts encoding GUS. Out of 17 isolated 5' sequences, in 14 the splice site A1 and in three A2 has been properly used to generate the reporter gene transcript. These findings are consistent with previous studies of GTDsB splice products in transiently transformed barley tissue, revealing that the splice acceptor sites A2 and A3 were utilized with almost equal frequencies but eleven times less frequent than A1 [31].

\section{Discussion}

With the development of an Ac/Ds based gene trap system in barley we contribute a novel functional genomics tool for this species. In our approach gene trapping efficiency 
Table 3: GUS expression in the $F_{2}$ generation of gene trap lines

\begin{tabular}{|c|c|c|c|c|}
\hline GTDsB line & Gene trap line & No. plants analysed & No. plants with GUS & Organ with GUS activity (no. explants) \\
\hline \multirow[t]{2}{*}{$2 \mathrm{a} / \mathrm{d}$} & GT32 & 6 & 2 & grain $(\mathrm{I})$, seedling $(\mathrm{I})$ \\
\hline & GT73 & 4 & 1 & grain (I) \\
\hline \multirow[t]{4}{*}{23} & GT33 & 4 & - & - \\
\hline & GT29 & $4(\mathrm{Ic})$ & 2 & pollinated floret $(\mathrm{I})$, seedling $(\mathrm{I})$ \\
\hline & GT39 & I & - & - \\
\hline & GT4I & 5 & 3 & pollinated floret (13), grain (4), seedling (I) \\
\hline \multirow[t]{2}{*}{$3 \mid \mathrm{B}$} & GT49 & 4 & 2 & pollinated floret (2), seedling (I) \\
\hline & GT54 & 5 & 5 & immature (7)/pollinated (I) floret, grain (10), seedling (15) \\
\hline \multirow[t]{3}{*}{$6 \mathrm{a} / \mathrm{c}$} & GT70 & 4 & 1 & pollinated floret $(I)$, node $(I)$ \\
\hline & GT67 & 6 & 4 & node (4), leaf (I) \\
\hline & GT4 & $7^{(\mathrm{la})}$ & - & - \\
\hline \multirow[t]{2}{*}{$3 \mid \mathrm{A}$} & GT38 & 6 & 1 & seedling (I) \\
\hline & GT52 & $5^{(I d / l e)}$ & 4 & node $(I)$, grain $(10)$ \\
\hline \multirow[t]{3}{*}{16} & GTI9 & $4^{b}$ & i & grain (I) \\
\hline & GT37 & 8 & 2 & grain (4), seedling (I) \\
\hline & GT40 & 4 & - & - \\
\hline \multirow[t]{2}{*}{$14 \mathrm{~A}$} & GTI3 & $4(2 b / 2 c)$ & 2 & grain (I), seedling (7) \\
\hline & GT22 & $5(4 b / I c)$ & 4 & grain (2), seedling (17) \\
\hline \multirow[t]{3}{*}{11} & GT82 & 3 & 3 & immature floret (I), node (3), leaf (I) \\
\hline & GT66 & $3(f)$ & 2 & pollinated floret (3), grain (I) \\
\hline & GT80 & 4 & 4 & $\begin{array}{l}\text { immature floret (3), pollinated floret (2), node (4), leaf (I), grain (9), } \\
\text { seedling (2) }\end{array}$ \\
\hline \multirow[t]{3}{*}{10} & GT9 & $7(7 b)$ & 2 & grain $(2)$, seedling $(2)$ \\
\hline & GT2 & $7(6 \mathrm{~b} / \mathrm{lc})$ & 5 & grain (2), seedling (4) \\
\hline & GT6 & $7(5 b / 2 c)$ & 4 & grain (6), seedling (3) \\
\hline \multirow[t]{2}{*}{ I4B } & GT23 & $4(2 a / / d)$ & 1 & seedling (I) \\
\hline & GTI5 & $8(1 \mathrm{lb} / 3 \mathrm{c})$ & 7 & pollinated floret (9), grain (12), seedling (17) \\
\hline \multirow[t]{2}{*}{26} & GT35 & 4 & 4 & immature floret (4I), pollinated floret (32) \\
\hline & GT63 & 8 & 7 & immature floret (3), grain (23), seedling (2) \\
\hline
\end{tabular}

\footnotetext{
(No. plants a) Only seedlings were analysed

(No. plants b)Only grains and seedlings were analysed

(No. plants c)Only pollinated florets, grains and seedlings were analysed

(No. plants d)No pollinated florets were analysed

(No. plants e)No grains were analysed

(No. plants f)Only immature florets, nodes and leafs were analysed
}

depends on transposition of the GTDsB construct. DNA gel blot analyses indicate frequent transposition of the GTDsB element in the gene trap lines. The transposition frequency of $11 \%(9 / 79)$ detected in the $F_{1}$ generation is in the range of the transposition frequency presented for the barley activation tagging system [28], but higher than that reported for transposition of Ds elements $(2 \%)$ and autonomous Ac elements (1.5\%) in $\mathrm{F}_{1}$ and $\mathrm{T}_{1}$ generations of barley $[25,26]$. In the $\mathrm{F}_{2}$ generation we observed in $26 \%$ $(49 / 191)$ of the plants unique newly transposed GTDsB elements, indicating a transposition frequency sufficient for large-scale mutagenesis screens in barley [28]. In addition, the rapid recovery of many independent GTDsB insertions will be potentiated by independent transposition events in the tillers of a single barley plant.

In rice and Arabidopsis extensive collections of insertion lines have been generated by high throughput T-DNA transformation. However, for large-genome and transformation-recalcitrant species like barley insertion mutagenesis strategies based on transposable elements are likely to be advantageous. A recent detailed study of T-DNA insertion distribution in rice revealed a preference for insertion into genic sequences, thus reducing the number of insertions needed to saturate the genome [39]. The barley genome supposedly contains the same number of genes like rice, but is due to amplification of gene-poor regions about 12 times larger [17]. Therefore, insertion mutagenesis merely based on T-DNA transformation would require far more than 200000 primary transformants. For barley these will be difficult to obtain given that barley transformation requires extensive tissue culture periods and is still laborious and relatively inefficient. By contrast, the transposon based approach enables with only a few initial starter lines the successive accumulation of novel independent insertions in a definite plant population 


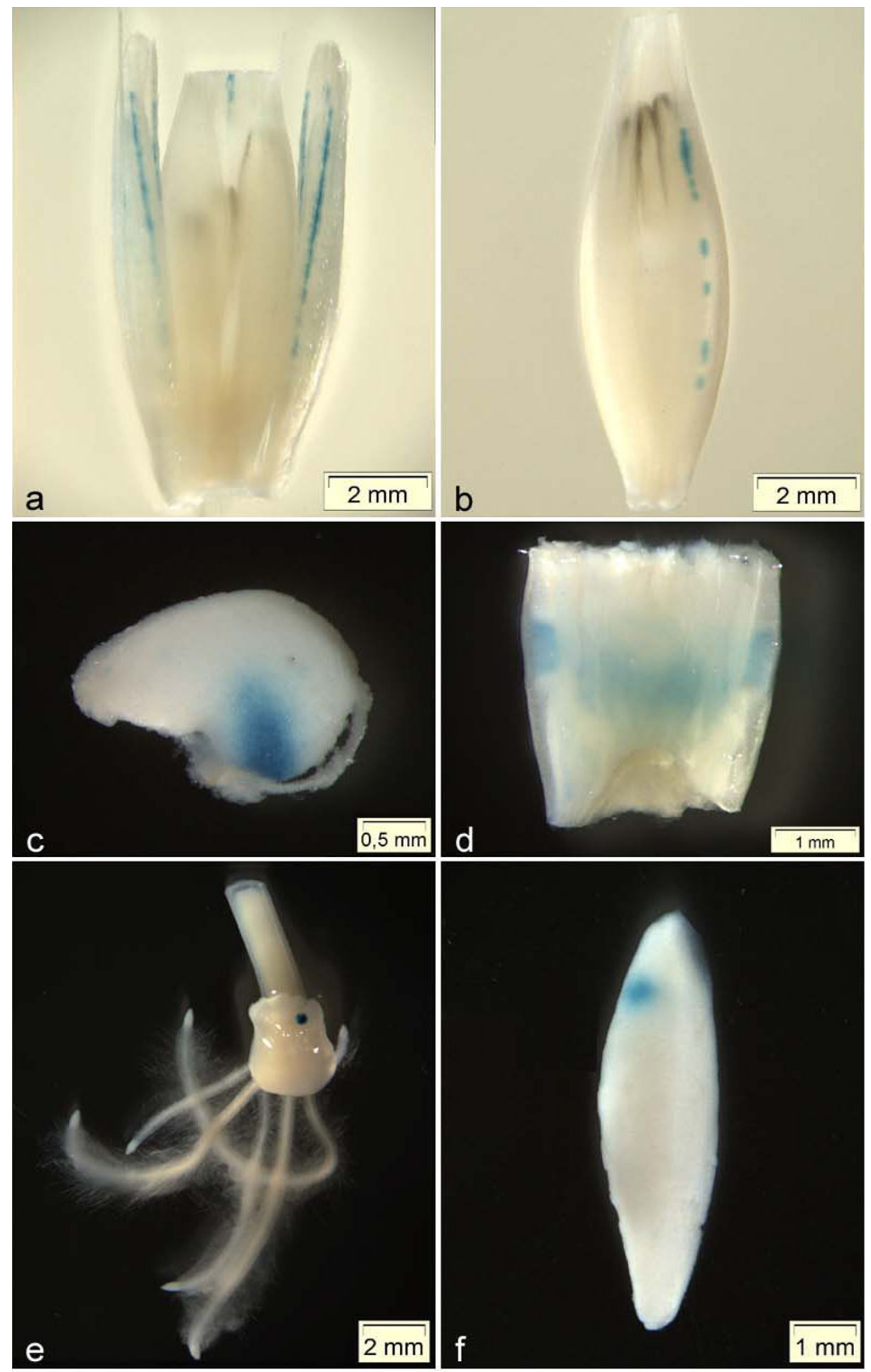

\section{Figure 3}

Examples of GUS expression in $\mathbf{F}_{2}$ plants. a GUS staining in the lemma of the central floret and the sterile lateral florets (GT35/8). b GUS staining in the lemma (GT29/6). c GUS staining in endosperm tissue (GTI5/9). d GUS staining in the node (GT4/I0). e GUS staining in scutellar tissue of a seedling (GT37/6). f GUS staining in endosperm tissue (GT80/I). 
Table 4: Gene trap $F_{2}$ plants with GUS expression in at least $50 \%$ of the explants

\begin{tabular}{llll}
\hline F plant & No. of explants analysed & No. of explants with GUS & Explant type \\
\hline GT4I/3 & 16 & 13 & pollinated florets \\
GT54/5 & 8 & 5 & seedlings \\
GT54/10 & 8 & 5 & seedlings \\
GTI3/8 & 8 & 5 & seedlings \\
GT22/3 & 8 & 6 & seedlings \\
GT22/5 & 8 & 8 & seedlings \\
GTI5/2 & 8 & 5 & seedlings \\
GT15/4 & 8 & 4 & seedlings \\
GTI5/9 & 9 & 9 & pollinated florets \\
GT35/1 & 8 & 8 & pollinated florets \\
GT35/3 & 8 & 8 & pollinated florets \\
GT35/7 & 8 & 8 & pollinated florets \\
GT35/8 & 8 & 8 & pollinated florets \\
GT63/4 & 16 & 9 & grains \\
\hline
\end{tabular}

$[28,40]$. In addition, a direct comparison of $A c$ and T-DNA insertions in aspen revealed for the transposable element a two fold higher frequency of landing into coding regions [41]. The preferential insertion into expressed genomic sequences is a feature of $A c / D s$ transposition, that has been well documented in barley $[12,13,27]$, Arabidopsis $[42,43]$ and rice $[44,45,40]$. This preference we also observed in the barley gene trap lines evident in the frequent identity of transposed GTDsB flanking genomic sequences to barley ESTs.

By using 11 independent GTDsB starter lines with a variable GTDsB copy number we generated a barley gene trap population comprising more than 40 putative GTDsB launch pads at different genomic positions. The transposition of GTDsB could be detected in progeny of crosses with each of the 11 GTDsB parental lines, demonstrating that every independent GTDsB line carries transposition competent constructs and can be utilized for gene trapping in barley. Although, currently no mapping populations are available for the barley variety used here, a sequence based strategy for assigning Ds insertions in Golden Promise to linkage map coordinates on the existing Oregon Wolfe Barley map has been reported [13]. Most agronomically important traits, such as yield and

Table 5: GUS expression frequency in various organs of $F_{2}$ plants

\begin{tabular}{llll}
\hline & & \multicolumn{2}{l}{ GUS positive plants } \\
\cline { 3 - 4 } Organ & No. of $F_{2}$ plants tested & No. & $\%$ \\
\hline leaf & 99 & 3 & 3 \\
node & 99 & 13 & 13 \\
immature floret & 99 & 9 & 9 \\
pollinated floret & 104 & 14 & 13 \\
grain & 134 & 35 & 26 \\
seedling & 138 & 33 & 24
\end{tabular}

quality parameters, are controlled by many genes arranged as so called "quantitative trait loci" (QTLs) [46]. GTDsB insertions nearby known QTLs will therefore provide useful launch pads for local saturation mutagenesis [47]. This approach will take advantage of the well documented $A c / D s$ feature of preferential transposition to chromosomally linked positions [48], equally observed in barley $[12,25]$.

Interestingly, the transposition frequency in the $\mathrm{F}_{2}$ generation ranges between 5\% (GTDsB 10) and 67\% (GTDsB 26 ), if calculated per independent GTDsB parental line. The variance of transposition frequency has been frequently observed in independent barley and rice transgenic lines $[25,28,40,44,45]$ and likewise in dicots [48]. Earlier studies have shown that $D s$ transposition is influenced by the genomic position of the element $[40,49]$. Our findings confirm that the transposition frequency is rather influenced by the GTDsB integration site than by the number of GTDsB loci. For example, unique transpositional activity of $67 \%$ and $50 \%$ was detected in gene trap lines originating from GTDsB parental lines 26 and 23 having 12 and 1-2 loci respectively. The DNA gel blot results indicate some correlation between GTDsB transpositional activity and TPase-expressing construct. $\mathrm{F}_{2}$ plants carrying one (TPase line 2) or four (TPase line 7) TPase ${ }_{103-}$ ${ }_{807}$ copies exhibit a noticeable higher transpositional activity of $26 \%$ ( 10 of 39 plants with transposition) and $27 \%$ (31 of 115 plants with transposition) than $F_{2}$ plants having two copies of wild type TPase (13\%, 4 of 30 plants with transposition). This finding is consistent with earlier reports, showing that the TPase ${ }_{103-807}$ induces higher excision frequencies of $D s$ than wild type TPase in Petunia protoplasts $[50,51]$ and transgenic tobacco [32].

Accurate and efficient splicing of the gene trap construct is a prerequisite for reporter gene expression and therefore 
crucial for gene trapping efficiency. GTDsB was optimized for efficient splicing in monocotyledonous plants by adapting the splice acceptor sites to the monocot consensus and the introduction of synthetic branch point and Ttract sequences [31]. An important feature in the optimization process was to attenuate the first splice acceptor site (A1; Figure 1b), since for splice acceptor site selection a scanning mechanism is postulated [52]. The isolated 5' sequences of GUS fusion transcripts indicate a preference for usage of the first splice acceptor site A1 according to former findings [31]. However, the isolation of three A2spliced GUS transcripts out of 17 analyzed indicates a decrease in A1 selection compared to the earlier transient studies [31]. With enhanced usage of A2 the chance of receiving functional GUS at a single integration site is increased by one third compared to exclusive usage of A1 emphasizing the potential of GTDsB for gene trapping.

We were primarily interested in detecting reporter gene expression in the gene trap population and, opposite to other transposon-based gene trap approaches $[5,6]$, did not select for plants with transposed GTDsB constructs prior to the analysis of GUS activity. We therefore expected (i) the GUS expression frequency to be lower than the frequencies of $26 \%$ and $16 \%$ reported in Arabidopsis and rice respectively [5,6] and (ii) to detect a high proportion of somatic events. To raise the probability of GUS detection, we decided to screen several organs containing differentiating and dividing cells. Additionally, for the majority of the organs multiple explants per single plant were tested for GUS activity, thus enabling to discriminate between somatic and transmissible events. This screening mode accounts for the high number of gene trap insertion events detected, since GUS expression was found in 72 of the $141 \mathrm{~F}_{2}$ plants (51\%). GUS expression was detected in progeny of all 11 GTDsB lines, which is not surprising as transposition of GTDsB was likewise found in progeny of crosses with all GTDsB parental lines. In 14 plants $(10 \%)$ GUS expression was detected in at least half of the explants of a single organ type, primarily in seedlings and florets, suggesting candidates for transmissible events and thus for gene identification. In a rice insertional mutagenesis approach employing a Ds based gene trap, GUS expression was observed in $8.1 \%$ of the lines analyzed [53]. However, the heritability of the events was not addressed. The higher GUS expression frequency of $26 \%$ in grains and $24 \%$ in seedlings in comparison to the remaining organs indicates the accumulation of insertion events in later generations and demonstrates the dependence of GUS expression on GTDsB transposition. In $\mathrm{F}_{3}$ tissues, in addition to events of the preceding generations, developmentally early transposition events can lead to detectable GUS expression. By contrast, in a TDNA based gene trap system in rice homogeneous GUS expression frequencies in leaves, roots, florets and immature grains were detected [10].

A particular challenge for plant functional genomics is the abundance of functional gene redundancy and multigene families [54,55]. About $15 \%$ of the identified genes in sequenced plant genomes are considered to be members of tandem-arrayed gene families [55]. Therefore in Arabidopsis less than $2 \%$ of gene knockouts are expected to display significant mutant phenotypes $[54,56]$. The gene trap approach may prove to be highly beneficial as indicated by the 6 to 30 times more frequent detection of GUS reporter gene expression compared to visible mutant phenotypes in Ac/Ds-mediated Arabidopsis gene trap lines $[5,57]$. The identification of genes whose recovery by lossof-function mutagenesis would have been impeded either by gene redundancy or a lethal phenotype [58-61] further emphasizes that gene trap insertional mutagenesis provides a powerful genomics strategy.

\section{Conclusion}

Barley has one of the largest genomes of all economically important cereal crops and even though more and more genomic sequence data are available various functional genomics resources will be needed to address questions of yield and stress resistance. With the Ac/Ds-mediated gene trap system in barley we adopt a novel functional genomics tool for this species. This will be valuable for both gene trapping and knockout mutation as well as forward and reverse genetic screens. In the gene trap lines we observed frequent transposition of the gene trap construct GTDsB from multiple launch sites sufficient for large-scale mutagenesis. The recovery of individual insertion events will be further assisted by the high number of independent insertions and the preferential transposition into expressed genomic sequences. Maintenance of transposition activity over several generations makes the gene trap lines applicable for the accumulation of independent insertions in a barley gene trap plant population. The frequent detection of GUS reporter gene expression in the gene trap lines and the proper splicing of our optimized gene trap construct finally prove gene trap insertional mutagenesis to be now attainable for barley functional genomics.

\section{Methods \\ Construct design}

To generate $\mathrm{cw} A c$ (clipped wing $A c$ ) containing an immobilized Ac element expressing wild type TPase under the regulatory control of the native $A c$ promoter, five base pairs of the $5^{\prime} A c$ end in PJAc [62] have been deleted according to Healy et al. [33]. For cwAc 102, expressing a transposase shortened by 102 amino acids at the N-terminus (TPase $\left.{ }_{103-807},[32]\right)$, the Ac element was immobilized in the same manner. The Ds based gene trap construct 
GTDsB carries a promoterless uidA gene preceded by a triple splice acceptor site [31].

\section{Plant material and transformation}

Immature embryos of barley (Hordeum vulgare L.; cv. Golden Promise) were transformed via particle bombardment either with GTDsB, cwAc or cwAc 102. To facilitate the selection of transgenic plants a synthetic pat gene (Peter Eckes, unpublished) encoding a phosphinotricin acetyltransferase that confers resistance to glufosinatetype herbicides was co-transformed. Transformation and regeneration of transgenic barley plants was performed as described by Scholz et al. [26]. Barley plants were grown in the greenhouse at $16-18^{\circ} \mathrm{C}$ day $/ 12-13^{\circ} \mathrm{C}$ night temperatures with a $16 \mathrm{~h}$ photoperiod.

\section{Generation of the gene trap population}

To generate the gene trap lines, plants carrying GTDsB constructs were crossed with plants expressing either wild type transposase (TPase) or an N-terminal truncated transposase (TPase (103-807 ). $\mathrm{F}_{1}$ plants containing TPase as well as GTDsB constructs were selected by PCR. Individual $F_{1}$ plants, also referred to as gene trap lines, were named GT followed by a unique number. For the $\mathrm{F}_{2}$ generation, progeny of 28 selfed $\mathrm{F}_{1}$ plants containing both constructs were selected in the same way. Likewise, the $\mathrm{F}_{3}$ and $\mathrm{F}_{4}$ generation was produced by two further rounds of selfing and PCR selection.

\section{Genomic DNA isolation and DNA gel blot analysis}

Genomic DNA was extracted from several leaf tips per plant as described by Palotta et al. [63]. To determine the copy number of GTDsB and TPase constructs, DNA from GTDsB and TPase plants was digested with BamHI, MunI or XbaI. The integration of intact GTDsB elements was proved by digestion with EcoRI and HindIII, which release a $3.5 \mathrm{~kb}$ fragment from the $\mathrm{pGTDsB}$ transformation vector containing the complete GTDsB cassette. The integration of intact TPase constructs was confirmed by digestion with BamHI and PacI. For analysis of transposition events the genomic DNA of $\mathrm{F}_{1}, \mathrm{~F}_{2}$ and $\mathrm{F}_{4}$ gene trap plants was digested with $B g l \mathrm{II}, \mathrm{BcuI}$ or BamHI, all cutting only once in the GTDsB element. Digested DNA was subjected to DNA gel blot analysis as described by Scholz et al. [26]. For the detection of GTDsB elements a 637 bp uidA fragment was digoxigenin labeled by PCR. The TPase specific probe was prepared by labelling a 734 bp Ac fragment with digoxigenin.

\section{Isolation and analysis of GTDsB flanking sequences}

DNA regions flanking GTDsB inserts in gene trap lines were amplified by TAIL-PCR as described [35,64]. $10 \mathrm{ng}$ of genomic DNA were used as template DNA. The specific primers for the GTDsB $5^{\prime}$ end were: R-GUS-A (5'CCCACAGGCCGTCGAGTTT-3')， R-GUS-1 (5'-CACG-
GGTTGGGGTTTCTACA-3') and 3pAH2-2.1 (5'-CCGTATTTATCCCGTTCGTTTTCGTTA-3'). The following arbitrary primers were used: AD1 (5'-NGTCGASWGANAWGAA-3'), AD2 (5'-GTNCGASWCANAWGTT-3'), AD3 (5'-WGTGNAGWANCANAGA-3'), AD4 (5'-NTCGASTWTSGWGTT-3'); AD5 (5'-NGTASASWGTNAWCAA3'), AD6 (5'-TGWGNAGWANCASAGA-3'), AD7 (5'AGWGNAGWANCAWAGG-3'), AD8 (5'-CAWCGICNGAIASGAA-3') and AD9 (5'-TCSTICGNACITWGGA-3'). Specific tertiary PCR fragments were purified from agarose gels with Recochips (TaKaRa, Shiga, Japan) and sequenced (DNA-Cloning-Service, Hamburg, Germany). The BLAST algorithm [65] was used to compare each sequence to the publicly available databases GenBank, EMBL/EBI and DDBJ.

\section{GUS histochemical analysis}

Plant material for GUS staining was collected from gene trap $\mathrm{F}_{2}$ plants considering the Zadoks code system for growth staging in barley [37]. Two nodes, one leaf and 20 florets were collected from one tiller at growth stage 49. Nodes were divided, leafs dissected and florets cut from the spike. To obtain the pollinated florets eight spikelets were collected from one ear at growth stage 65-69. The awns of all florets were cut off, while sterile lateral spikelets were partially kept. At growth stage 83-85, eight grains were collected from one ear and divided after the removal of the lemma and palea. For seedling analysis, eight embryos were isolated from one ear and germinated for five days on sterile plates. Expression of GUS in barley tissues was assayed essentially as described by Jefferson [66] and Dai et al. [67]. Materials, with the exception of grains, were pre-treated with $90 \%$ acetone for $2 \mathrm{~h}$ at $20^{\circ} \mathrm{C}$. Grains were pre-treated with $70 \%$ ethanol for $2 \mathrm{~min}$. Explants were washed twice in $50 \mathrm{mM}$ sodium phosphate (pH 7) transferred into microtiter wells containing GUS staining solution $(50 \mathrm{mM}$ sodium phosphate $\mathrm{pH} \mathrm{7,10}$ mM EDTA, 0,05\% Triton-X 100, $100 \mu \mathrm{g} / \mathrm{ml}$ Chloramphenicol, $1 \mathrm{mM} \mathrm{X-Gluc),} \mathrm{vacuum} \mathrm{infiltrated} \mathrm{for} 2 \mathrm{~min}$ and incubated at $37^{\circ} \mathrm{C}$ for $24 \mathrm{~h}$. Tissues were cleared by several changes of $96 \%$ ethanol and stored in $75 \%$ ethanol. The samples were observed under a light microscope (SZX9, Olympus, Japan) and images captured using a CCD camera (ColorView, Olympus, Japan) and appropriate software (analySIS, Soft Imaging System GmbH, Münster, Germany).

\section{5'RACE (rapid amplification of cDNA ends)}

Total RNA was extracted as described by Chomczynski and Sacchi [68] from sterile lateral spikelets of gene trap line GT35. $1 \mu \mathrm{g}$ was used as a template in a reverse transcription reaction (Thermoscript Reverse Transcriptase, Invitrogen, Karlsruhe, Germany) with a gene specific primer (GSP) binding to the uidA coding region in GTDsB (R-GUS-D, 5'-CGCTGGCCTGCCCAACCTTT-3'). After 
RNA degradation with RNase H (Invitrogen, Karlsruhe, Germany) a homopolymeric tailing reaction with Terminal Deoxynucleotidyl Transferase (MBI Fermentas, St.Leon-Rot, Germany) and dGTP was carried out. The tailed cDNA was used as a template in a PCR with a tail binding Primer (CB3, 5'-CCCCCCCCTCCCCCCC-3', H. Schmidt, unpublished) and a nested GSP (R-GUS-B, 5'CGCGCTTTCCCACCAACGCT-3'). $1 \mu \mathrm{l}$ PCR product was subjected to a second PCR with CB3 and a third GSP (RGUS-A, 5'-CCCACAGGCCGTCGAGTTT-3'). Specific DNA fragments were extracted from agarose gels and subcloned for analysis.

\section{Authors' contributions}

KL designed the study, performed the experimental work and wrote the manuscript. SL provided GTDsB and TPase barley lines, participated in the analysis of GTDsB flanking sequences, in the design and coordination of the study and in the writing of the manuscript. All authors read and approved the final manuscript.

\section{Acknowledgements}

We thank Meike Andermann, Sabine Grünberg and Angela Kahl for excellent technical support; C.K. Friedrich and Sirkka Scheef for kindly providing unpublished data and TPase plants; Jutta Krüger for images of plant material and Reinhard Kunze for critical comments on the manuscript. This work was supported by a Studienstiftung des Deutschen Volkes PhD fellowship to $\mathrm{KL}$. The experimental data presented here partly appeared in the doctoral thesis of $\mathrm{KL}$.

\section{References}

I. Cecconi F, Meyer BI: Gene trap: a way to identify novel genes and unravel their biological function. FEBS Letters 2000, 480:63-7I.

2. Stanford WL, Cohn JB, Cordes SP: Gene trap-mutagenesis: past, present and beyond. Nat Rev Genet 200I, 2(10):756-768.

3. Springer PS: Gene traps: Tools for Plant Development and Genomics. Plant Cell 2000, I 2:1007-1020.

4. Kunze R, Saedler H, Lönning WE: Plant Transposable Elements. In Advances in Botanical Research Volume 27. Edited by: Callow JA. San Diego Academic Press; 1997:332-470.

5. Sundaresan V, Springer P, Volpe T, Haward S, Jones JDG, Dean C, Ma $H$, Martienssen R: Patterns of gene action in plant development revealed by enhancer trap and gene trap transposable elements. Genes Dev 1995, 9:1797-1810.

6. Chin HG, Choe MS, Lee SH, Park SH, Koo JC, Kim NY, Lee J], Oh BG Yi GH, Kim SC, Choi HC, Cho MJ, Han CD: Molecular analysis of rice plants harbouring an Ac/Ds transposable element-mediated gene trapping system. Plant I 1999, 19:615-23.

7. Babiychuk E, Fuangthong M, Van Montagu M, Inzé D, Kushnir S: Efficient gene tagging in Arabidopsis thaliana using a gene trap approach. Proc Natl Acad Sci USA 1997, 94:| 2722-I 2727.

8. Yamamoto YY, Tsuhara Y, Gohda K, Suzuki K, Matsui M: Gene trapping of the Arabidopsis genome with a firefly luciferase reporter. Plant J 2003, 35:273-283.

9. Alvardo MC, Zsigmond LM, Kovács I, Cséplö Á, Konzc C, Szabados LM. Gene trapping with firefly luciferase in Arabidopsis. Tag ging of stress responsive genes. Plant Physiol 2004, I 34: I8-27.

10. Jeon JS, Lee S, Jung KH, Jun SH, Jeong DH, Lee J, Kim C, Jang S, Yang K, Nam J, An K, Han MJ, Sung RJ, Choi HS, Yu JH, Choi JH, Cho SY, Cha SS, Kim SI, An G: T-DNA insertional mutagenesis for functional genomics in rice. Plant $\int 2000,22: 561-570$.

II. Hiwatshi Y, Nishiyama T, Fujita T, Hasebe M: Establishment of gene-trap and enhancer-trap systems in the moss Physcomitrella patens. Plant J 200I, 28:105-116.
12. Zhao T, Palotta M, Langridge P, Prasad M, Graner A, Schulze-Lefert P, Koprek T: Mapped Ds/T-DNA launch pads for functional genomics in barley. Plant J 2006, 47:8I I-826.

13. Cooper LD, Marquez-Cedillo L, Singh J, Sturbaum AK, Zhang S, Edwards V, Johnson K, Kleinhofs A, Rangel S, Carollo V, Bregitzer P, Lemaux PG. Hayes PM: Mapping Ds insertions in barley using a sequence-based approach. Mol Genet Genomics 2004, 272: $181-193$.

14. Moore G, Devos KM, Wang ZM, Gale MD: Cereal genome evolution. Grasses, line up and form a circle. Curr Biol 1995, 5:737-739.

15. Kunzel G, Korzun L, Meister A: Cytologically integrated physical restriction fragment length polymorphism maps for the barley genome based on translocation breakpoints. Genetics 2000, I54:397-4I2.

16. Arumuganathan K, Earle ED: Nuclear DNA content of some important plant species. Plant Mol Biol Rep 199|, 9:208-2।8.

17. Sandhu D, Gill KS: Gene-containing regions of wheat and the other grass genomes. Plant Physiol 2002, I 28(3):803-8I I.

18. Wicker T, Narechania A, Sabot F, Stein J, Vu GTH, Graner A, Ware $D$, Stein $N$ : Low-pass shotgun sequencing of the barley genome facilitates rapid identification of genes, conserved non-coding sequences and novel repeats. BMC Genomics 2008, 9:518.

19. Yu Y, Tomkins JP, Waugh R, Frisch DA, Kudrna D, Kleinhofs A, Brueggeman RS, Muehlbauer G], Wise RP, Wing RA: A bacterial artificial chromosome library for barley (Hordeum vulgare L.) and the identification of clones containing putative resistance genes. Theor Appl Genet 2000, I 01: 1093-1099.

20. Close TJ, Wanamaker SI, Caldo R-A, Turner AM, Ashlock DA, Dickerson JA, Wing RA, Muehlbauer G], Kleinhofs A, Wise RP: A new resource for cereal genomics: $22 \mathrm{~K}$ barley genechip comes of age. Plant Physiol 2004, 134:960-968.

2I. Varshney RK, Grosse I, Hähnel U, Siefken R, Prasad M, Stein N, Langridge P, Altschmied L, Graner A: Genetic mapping and BAC assignment of EST-derived SSR markers shows non-uniform distribution of genes in the barley genome. Theor Appl Genet 2006, II 3:239-250.

22. Jähne $A$, Becker $D$, Brettschneider R, Lörz $H$ : Regeneration of transgenic, microspore-derived, fertile barley. Theor Appl Genet 1994, 89:525-533.

23. Wan Y, Lemaux PG: Generation of large numbers of independently transformed fertile barley plants. Plant Physiol 1994, 104:37-48.

24. Tingay S, McElroy D, Kalla R, Fieg S, Wang M, Thornton S, Brettell R Agrobacterium tumefaciens-mediated barley transformation. Plant J 1997, II:1369-1376.

25. Koprek T, McElroy D, Louwerse J, Williams-Carrier R, Lemaux PG An efficient method for dispersing $D s$ elements in the barley genome as a tool for determining gene function. Plant I 2000 24:253-263.

26. Scholz S, Lörz H, Lütticke S: Transposition of the maize transposable element Ac in barley (Hordeum vulgare L.). Mol Gen Genet 200I, 264:653-66I.

27. Singh J, Zhang S, Chen C, Cooper L, Bregitzer P, Sturbaum A, Hayes PM, Lemaux PG: High-frequency Ds remobilization over multiple generations in barley facilitates gene tagging in large genome cereals. Plant Mol Biol 2006, 62:937-950.

28. Ayliffe MA, Pallotta M, Langridge $P$, Pryor A): A barley activation tagging system. Plant Mol Biol 2007, 64:329-347.

29. Wu C, Li X, Yuan W, Chen G, Kilian A, Li J, Xu C, Li X, Zhou D-X Wang S, Zhang Q: Development of enhancer trap lines for functional analysis of the rice genome. Plant J 2003, 35:4I8-427.

30. Johnson AAT, Hibberd JM, Gay C, Essah PA, Haseloff J, Tester M, Guideroni $E$ : Spatial control of transgene expression in rice (Oryza sativa L.) using the GAL4 enhancer trapping system. Plant J 2005, 41:779-789.

31. Bergmann C, Lütticke S: Analysis of splice donor and acceptor function in a novel Ac-based gene trap construct. Planta 2004 21 9:876-883.

32. Kunze R, Kühn S, Jones JD, Scofield SR: Somatic and germinal activities of maize Activator (Ac) transposase mutants in transgenic tobacco. Plant J 1995, 8:45-54.

33. Healy J, Corr C, DeYoung J, Baker B: Linked and unlinked transposition of a genetically marked Dissociation element in transgenic tomato. Genetics 1993, 134:57I-584. 
34. McElroy D, Louwerse J, McElroy S, Lemaux PG: Development of a simple transient assay for Ac/Ds activity in cells of intact barley tissue. Plant J 1997, I I: I57-165.

35. Liu YG, Mitsukawa N, Oosumi T, Whittier RF: Efficient isolation and mapping of Arabidopsis thaliana T-DNA insert junctions by thermal asymmetric interlaced PCR. Plant J 1995, 8:457-463.

36. Barakat A, Carels N, Bernardi G: The distribution of genes in the genomes of Graminae. Proc Natl Acad Sci USA 1997 94:6857-686I.

37. Chang TT, Konzak CF, Zadoks JC: A decimal growth code for the growth stages of cereals. Weed Research 1974, 14:4I5-42 I.

38. Frohman MA: Rapid amplification of complementary DNA ends for generation of full-length complementary DNAs: thermal RACE. Methods in Enzymology 1993, 2 I 8:340-356.

39. Zhang J, Guo D, Chang Y, You C, Li X, Dai X, Weng Q, Zhang J, Chen G, Li X, Liu H, Han B, Zhang Q, Wu C: Non-random distribution of T-DNA insertions at various levels of the genome hierarchy as revealed by analyzing 13804 T-DNA flanking sequences from an enhancer trap mutant library. Plant J 2007 , 49:947-959.

40. Kolesnik T, Szeverenyi I, Bachmann D, Kumar CS, Jiang S, Ramamoorthy R, Cai M, Ma ZG, Sundaresan V, Ramachandran S: Establishing an efficient $A c / D s$ tagging system in rice: large-scale analysis of Ds flanking sequences. Plant J 2004, 37:30I-3।4

4l. Kumar S, Fladung M: Somatic mobility of the maize element Ac and its utility for gene tagging in aspen. Plant Mol Biol 2003 5 I:643-650

42. Parinov S, Sevugan M, Ye D, Yang WC, Kumaran M, Sundaresan V: Analysis of flanking sequences from dissociation insertion lines: a database for reverse genetics in Arabidopsis. Plant Cell 1999, I I:2263-2270.

43. Ito T, Motohashi R, Kuromori T, Mizukado S, Sakurai T, Kanahara H, Seki M, Shinozaki K: A new resource of locally transposed Dissociation elements for screening gene-knockout lines in silico on the Arabidopsis genome. Plant Physiol 2002, I29:1695-1699.

44. Enoki H, Izawa T, Kawahara M, Komatsu M, Koh S, Kyozuka J, Shimamoto K: Ac as a tool for the functional genomics of rice. Plant J 1999, 19:605-613.

45. Greco R, Ouwerkerk PB, Taal AJ, Favilli C, Beguiristain T, Puigdomènech $P$, Colombo L, Hoge $J \mathrm{H}$, Pereira A: Early and multiple Ac transpositions in rice suitable for efficient insertional mutagenesis. Plant Mol Biol 200I, 46:2I5-227.

46. Collard BCY, Jahufer MZZ, Brouwer JB, Pang ECK: An introduction to markers, quantitative trait loci (QTL) mapping and marker-assisted selection for crop improvement: The basic concepts. Euphytica 2005, I42: I69-196.

47. Ito T, Seki M, Hayashida N, Shibata D, Shinozaki K: Regional insertion mutagenesis of genes on Arabidopsis thaliana chromosome $V$ using the $A c / D$ s transposon in combination with a cDNA scanning method. Plant j 1999, I 7:433-444.

48. Kunze R: The maize transposable element activator (Ac). Curr Top Microbiol Immunol 1996, 204: I6I-194.

49. Bancroft I, Dean C: Factors affecting the excision frequency of the maize transposable element Ds in Arabidopsis thaliana. Mol Gen Genet 1993, 240:65-72.

50. Houba-Hérin N, Becker D, Post A, Larondelle Y, Starlinger P: Excision of a Ds-like maize transposable element (Ac delta) in a transient assay in Petunia is enhanced by a truncated coding region of the transposable element Ac. Mol Gen Genet 1990, 224: 17-23.

5I. Becker D, Lütticke R, Li M-G, Starlinger P: Control of excision frequency of maize transposable element Ds in Petunia Protoplasts. Proc Natl Acad Sci USA 1992, 89:5552-5556.

52. Smith CW, Chu TT, Nadal-Ginard B: Scanning and competition between AGs are involved in 3'splice site selection in mammalian introns. Mol Cell Biol 1993, I3:4939-4952.

53. Jiang S-Y, Bachmann D, La H, Ma Z, Venkatesh PN, Ramamoorthy R, Ramachandran S: Ds insertion mutagenesis as an efficient too to produce diverse variations for rice breeding. Plant $\mathrm{Mol} B i o l$ 2007, 65:385-402

54. Bouche N, Bouchez D: Arabidopsis gene knockout: phenotypes wanted. Curr Opin Plant Biol 2001, 4:1111-117.

55. Jander G, Barth C: Tandem gene arrays: a challenge for functional genomics. Trends Plant Sci 2007, I 2:203-2 I0.
56. Meinke DW, Meinke LK, Showalter TC, Schissel AM, Mueller LA Tzafrir I: A sequence-based map of Arabidopsis genes with mutant phenotypes. Plant Physiol 2003, I 3 I (2):409-4I 8.

57. Nakayama N, Arroyo JM, Simorowski J, May B, Martienssen R, Irish VF: Gene trap lines define domains of gene regulation in Arabidopsis petals and stamens. Plant Cell 2005, I 7:2486-2506.

58. Springer PS, McCombie WR, Sundaresan V, Martienssen : Gene-trap tagging of PROLIFERA, an essential MCM2-3-5-like gene in Arabidopsis. Science 268:877-880.

59. Dubreucq B, Berger N, Vincent E, Boisson M, Pelletier G, Caboche M, Lepiniec L: The Arabidopsis AtEPRI extensin-like gene is specifically expressed in endosperm during seed germination. Plant | 2000, 23:643-652

60. Yoshioka Y, Kurei S, Machida Y: Identification of a monofunctional aspartate kinase gene of Arabidopsis thaliana with spatially and temporally regulated expression. Genes Genet Syst 2001, 76:189-198.

6I. Jung $\mathrm{KH}$, Hur J, Ryu $\mathrm{CH}$, Choi Y, Chung YY, Miyao A, Hirochika $\mathrm{H}$ An G: Characterization of a rice chlorophyll-deficient mutant using the T-DNA gene trap system. Plant Cell Physiol 2003, 44:463-472

62. Kunze R, Stochaj U, Laufs J, Starlinger P: Transcription of the transposable element Activator (Ac) of Zea mays L. EMBO J 1987, 6:1555-1563.

63. Palotta MA, Graham RD, Langridge P, Sparrow DHB, Barker SJ: RFLP mapping of manganese efficiency in barley. Theor App Genet 2000, I0 I:I 100-1 I08.

64. Liu YG, Whittier RF: Thermal asymmetric interlaced PCR: automatable amplification and sequencing of insert end fragments from PI and YAC clones for chromosome walking. Genomics 1995, 25:674-81.

65. Altschul S, Gish W, Miller W, Myers E, Lipman D: Basic local alignment search tool. J Mol Biol 1990, 21 5:403-410.

66. Jefferson RA, Kavanagh TA, Bevan MW: GUS fusions: beta-glucuronidase as a sensitive and versatile gene fusion marker in higher plants. EMBO J 1987, 6:3901-3907.

67. Dai Z, Gao J, An K, Lee JM, Edwards GE, An G: Promoter elements controlling developmental and environmental regulation of a tobacco ribosomal protein gene L34. Plant Mol Biol 1996, 32:1055-1065.

68. Chomczynski P, Sacchi N: Single-step method of RNA isolation by acid guanidinium thiocyanate-phenol-chloroform extraction. Anal Biochem 1987, 162:156-159.

Publish with Biomed Central and every scientist can read your work free of charge

"BioMed Central will be the most significant development for disseminating the results of biomedical research in our lifetime. "

Sir Paul Nurse, Cancer Research UK

Your research papers will be:

- available free of charge to the entire biomedical community

- peer reviewed and published immediately upon acceptance

- cited in PubMed and archived on PubMed Central

- yours - you keep the copyright

BioMedcentral 